\title{
Políticas públicas de formação continuada de professores dos anos iniciais em Matemática
}

\section{Public policies on continuing education of teachers of elementary school's first years in mathematics}

\author{
Sueli Fanizzi ${ }^{1}$ \\ Vinício de Macedo Santos ${ }^{2}$
}

\begin{abstract}
Resumo
Este estudo investiga as políticas públicas de formação continuada de professores dos anos iniciais, em Matemática, da Secretaria Municipal de Educação de São Paulo, no período de 2005 a 2012, a partir da análise de documentos, da observação de encontros de formação continuada e de entrevista com professores. Como base no ciclo contínuo de políticas públicas de Stephen Ball, pode-se afirmar que não há uma aplicação imediata daquilo que é estabelecido nos textos oficiais e que não há, por parte do professor, apropriação e uso direto das orientações recebidas em encontros de formação continuada. Entre a determinação de uma política pública e a aprendizagem do aluno, há várias interpretações dos textos e ações oficiais e, consequentemente, descontinuidades. Conclui-se que a formação continuada mais adequada é aquela que oferece ao docente um espaço onde sua "voz", constituída pelas recontextualizações que ele faz do currículo e do ensino da Matemática, seja, de fato, considerada.
\end{abstract}

Palavras-chave: Formação continuada de professores; anos iniciais do ensino fundamental; ensino de Matemática; ciclo contínuo de políticas públicas.

\begin{abstract}
This study investigates public policies on continuing education of elementary school's first years Mathematic teachers from São Paulo Municipal Education Department from 2005 to 2012, based on analyses of documents, tracking of upbringing meetings, and interviews with teachers. Based on Stephen Ball's ideas on public policies continued cycle we may say there is no immediate application of what is established in official documents, even when teachers appropriate and use educational guidance received in continued upbringing meetings. Between an educational official intent and the student apprenticeship there are different interpretations of official documents and actions, therefore provoking discontinuities. The conclusion is that the most adequate modality of continuing education is the one which provides teachers a space where their "voice", constituted by the recontextualizations he makes of the curriculum and the teaching of Mathematics, is, in fact, considered.
\end{abstract}

Keywords: teachers' continuing education; elementary school first years; Mathematic teaching; public policies continued cycle.

\footnotetext{
${ }^{1}$ Doutora em Educação pela Universidade de São Paulo. Professora da Universidade de Mogi das Cruzes, Brasil. Email: sfanizzi@usp.br

2 Professor Titular pela Universidade de São Paulo. Professor da Universidade de São Paulo, Brasil. Email: vms@usp.br
} 


\section{Introdução}

O sistema educacional brasileiro enfrenta mudanças significativas na década de 1990, influenciadas por mudanças locais, pelas reformas educacionais de outros países e pelo movimento da globalização, de transformação econômica, política, cultural e social. O foco dessas transformações direciona-se para os resultados, a consequente produtividade e a valorização das realidades locais.

Organismos e Programas internacionais como a Organização para a Cooperação e Desenvolvimento Econômico (OCDE), o Banco Mundial, a Organização das Nações Unidas para a Educação, a Ciência e a Cultura (UNESCO) e o Programa Internacional da Avaliação de Estudantes (PISA) orientam e apoiam as nações para a realização de reformas na área da Educação. Essa ordem externa, mundial, indutora e reguladora encontra-se e harmoniza-se com o terreno fértil de uma ordem interna, local, reverente, suscetível e centralizadora do poder público brasileiro (nas instâncias federal, estadual e municipal), porém coloca-se de costas para os anseios e vozes dos principais atores do sistema educacional - os professores -, em nome de um padrão de qualidade universal de ensino.

Stephen Ball, sociólogo britânico, que desenvolve estudos sobre as políticas públicas curriculares do Reino Unido, destaca um trecho do relatório da OCDE, de 1995, cujo conteúdo ele denomina de "reveladora mescla de descrição e prescrição" (Ball, 2001, p. 103) dos aspectos do movimento da globalização:

- atenção mais focada nos resultados em termos de eficiência, eficácia e qualidade dos serviços;

- substituição de estruturas organizacionais profundamente centralizadas e hierarquizadas por ambientes de gestão descentralizados, onde as decisões sobre a alocação de recursos e a prestação de serviços são tomadas muito mais próximas do local de prestação e onde há a criação de condições para a existência de feedback dos clientes e de outros grupos de interesse;

- flexibilidade para explorar alternativas para a provisão e regulação públicas que podem, por sua vez, levar a resultados mais eficazes em termos de custos;

- maior ênfase na eficiência dos serviços prestados diretamente pelo setor público, envolvendo o estabelecimento de objetivos de produtividade e a criação de ambientes competitivos dentro e entre as organizações do setor público;

- fortalecimento das habilidades estratégicas do poder central que conduzam à evolução do Estado e permitam que este responda aos desafios externos e interesses diversos de uma forma automática, flexível e a um custo reduzido. (Ball, 2001, p. 104)

No Brasil, as políticas públicas educacionais passam a adotar um discurso marcado pela qualidade de ensino, pelo desempenho e pela competência, significantes que definem o tom da produção de textos e outras ações governamentais concretizadas na década de 1990. Nesse contexto, inicia-se a cultura da avaliação dos sistemas 
DOI: http://dx.doi.org/10.20396/zet.v25i3.8648349

educacionais, inaugurada pelo Sistema Nacional de Avaliação da Educação Básica (SAEB) e, posteriormente, a partir de 2005, praticada em larga escala com a instituição da Prova Brasil. Em 2007, é criado o Índice de Desenvolvimento da Educação Básica (IDEB), calculado pelos dados sobre a aprovação escolar e as médias de desempenho nas avaliações oficiais. Essas mudanças, orientadas para garantir a sistemática de avaliações oficiais, têm impactado as práticas escolares, mobilizando a gestão, o corpo docente e os demais funcionários a encontrarem estratégias e procedimentos eficazes, de modo que as escolas melhorem os resultados de seus alunos nessas avaliações. Nesse contexto, a escola se ajusta a um modelo de qualidade associada ao desempenho dos alunos em testes externos aplicados em larga escala.

Na gestão iniciada no ano de 2005, a Secretaria Municipal de Educação de São Paulo (SME-SP) depara-se, naquele mesmo ano, com um IDEB das escolas municipais do município aquém do esperado, ou pelo menos inferior ao das escolas estaduais do estado de São Paulo, considerando o término do ciclo dos anos iniciais do ensino fundamental. ${ }^{3}$ Com a intenção de melhorar o desempenho dos alunos e reverter os resultados das avaliações externas e, consequentemente o IDEB, são criadas, na gestão Serra-Kassab ${ }^{4}$, políticas públicas educacionais por meio de diferentes ações da SMESP, já a partir de 2005, logo após a posse do novo governo.

Apesar do massivo investimento na elaboração de materiais para coordenadores, professores e alunos, na definição de orientações curriculares para as escolas municipais e em ações voltadas para a formação continuada de professores ao longo de toda a gestão, em 2011, após oito anos, nota-se que os índices de proficiência em Língua Portuguesa e Matemática e, de maneira geral, o IDEB, embora melhores, continuam aquém do nível esperado, tanto no Ciclo 1 como no Ciclo 2 do ensino fundamental ${ }^{5}$ das escolas municipais do município de São Paulo ${ }^{6}$. Pode-se, dessa forma, formular a seguinte indagação: por que o cenário dos resultados do desempenho dos alunos é modificado de forma tão inexpressiva após todos esses investimentos?

\footnotetext{
${ }^{3}$ Em 2005, o IDEB do município de São Paulo foi 4,1 e do estado de São Paulo, 4,5. A meta da gestão da SME-SP, iniciada em 2005, para o final de 2011 - ano anterior à conclusão do mandato - era 4,9, e para 2013, 5,2, o que demonstra uma distância significativa entre o índice do qual a gestão partiu e o índice almejado. Fonte: INSTITUTO NACIONAL DE ESTUDOS E PESQUISAS EDUCACIONAIS ANÍSIO TEIXEIRA. Ideb: resultados e metas. Brasília, DF: MEC/SEB/INEP, 2014. Disponível em: <http://ideb.inep.gov.br/resultado/>. Acesso em: 21 fev. 2017.

${ }^{4}$ José Serra foi prefeito de São Paulo em 2005 e 2006. Renunciou ao cargo para se candidatar ao governo do estado de São Paulo nas eleições de outubro de 2006. Gilberto Kassab assumiu a prefeitura e se reelegeu em 2008, governando a cidade até 2012.

${ }^{5} \mathrm{Na}$ época desse estudo, os anos de escolaridade do ensino fundamental da Rede Municipal de Ensino de São Paulo eram agrupados em dois ciclos: Ciclo 1 ( $1^{\circ}$ ao $5^{\circ}$ ano $)$ e Ciclo 2 ( $6^{\circ}$ ano $9^{\circ}$ ano).

6 Na tese, cujo título corresponde ao deste artigo, há outros quadros que apresentam informações específicas sobre a evolução dos níveis de desempenho em Língua Portuguesa e Matemática dos alunos do Ciclo 1, de escolas da Rede Municipal de Ensino de São Paulo, entre os anos de 2007 a 2012.
} 
DOI: http://dx.doi.org/10.20396/zet.v25i3.8648349

Este estudo teve por objetivos investigar como a SME-SP concebe e implementa as políticas públicas de formação continuada de professores ao longo da gestão de 2005 a 2012 e compreender a repercussão dessas ações na "voz" de professores dos anos iniciais do ensino fundamental que participam de encontros de formação continuada, em Matemática, oferecidos pela instância oficial. Para tanto, buscou-se responder as seguintes perguntas: a) quais concepções de professor e de formação continuada de professores são expressas nos documentos publicados pela gestão de 2005 a 2012 da SME-SP? b) Quais concepções de professor e de formação continuada de professores são expressas em encontros de formação continuada oferecidos pela SME-SP a professores do $4^{\circ}$ ano do ensino fundamental de oito anos (equivalente ao $5^{\circ}$ ano do ensino fundamental de nove anos)? c) De que maneira o professor expressa a relação entre as políticas públicas da SME-SP - documentos oficiais e formação continuada de professores - e o seu trabalho?

\section{Quadro teórico}

Desenvolver uma investigação sobre a repercussão de políticas públicas voltadas para a formação continuada de professores implica analisar o tema em diferentes contextos pelos quais ele circula, dos textos curriculares - que contêm uma concepção, explícita ou implícita, de professor e de formação de professores - à sala de aula, espaço no qual a prática docente se concretiza. Parte-se do princípio de que não há relação direta entre o que o professor vivencia nos encontros de formação continuada, o que ele realmente faz na sala de aula e a aprendizagem dos alunos. Por exemplo, considerando o ensino de Matemática nos anos iniciais de escolaridade, um professor que compreende as orientações de trabalho com o algoritmo da multiplicação apresentadas pelo formador em um encontro de formação continuada não utiliza necessariamente a nova metodologia com seus alunos e, mesmo que a utilize, os alunos nem sempre são bemsucedidos na tarefa de efetuar as técnicas algorítmicas.

Muitas variáveis, pertencentes a diferentes esferas educacionais, cercam a prática docente, tais como o currículo e a concepção de professor nele presente, a formação continuada, oferecida em âmbito federal, estadual ou municipal, a escolha do livro didático, a disponibilidade de recursos na sala de aula, a relação do professor com o coordenador da escola, as condições de trabalho, dentre outras. Considerando a importância de uma análise integral, conjunta e relacional desses fatores constitutivos da prática docente, são adotados, como referenciais teóricos desta pesquisa, a abordagem de Stephen Ball, sobre políticas públicas educacionais, e estudos propriamente relacionados à formação de professores e à formação continuada de professores, com destaque para o ensino de Matemática.

\section{A perspectiva de Stephen Ball sobre políticas públicas educacionais}

De modo geral, embora prevaleça nas instâncias governamentais a ordem burocrática de aplicabilidade entre políticas públicas e prática docente, optou-se pelas 
DOI: http://dx.doi.org/10.20396/zet.v25i3.8648349

ideias de Ball $(2001,2006)$, que contraria essa perspectiva e apresenta ideias sobre a relação cíclica e permanente entre os diferentes contextos das políticas públicas e, consequentemente, entre as "vozes" que as produzem.

As políticas normalmente não nos dizem o que fazer, elas criam circunstâncias nas quais o espectro de opções disponíveis sobre o que fazer é reduzido ou modificado ou nas quais metas particulares ou efeitos são estabelecidos. Uma resposta ainda precisa ser construída no contexto, contraposta ou balanceada por outras expectativas. (Ball, 2006, p. 26)

Ball (2001) defende a integração entre as esferas global e local, isto é, entre o macrocontexto e o microcontexto, sem privilegiar um ou outro, e é a partir dessa perspectiva que ele desenvolve seu modelo de análise das políticas públicas educacionais, ou seja, o ciclo contínuo de políticas.

Analisar as políticas públicas por meio de uma abordagem conjunta do "globallocal" requer o distanciamento da concepção de que, sejam elas voltadas para a produção de um currículo oficial ou para a definição de programas de formação continuada de professores, são lançadas nas escolas, pelas instâncias governamentais, "de cima para baixo", cabendo a cada instituição a decisão sobre como recepcionar tais políticas: acatando e implementando o "pacote" de ações ou resistindo a ele. Segundo Lopes (2006), a proposta de Ball é exatamente a de romper com o par dicotômico acatar/resistir, lançando um olhar para outros sentidos que vão se constituindo ao longo do percurso pelo qual as políticas públicas transitam.

$\mathrm{Na}$ ideia inicial de ciclo de políticas, Ball (2001) já adota os termos "rede" e "arena" para analisar, de maneira relacional, as várias "vozes" que circulam nas políticas públicas educacionais, com o intuito de não tender ao que muitos estudos fazem, destacando ora o aspecto macrocontextual ou global, ora o aspecto microcontextual ou local. O termo rede indica a interdependência e os cruzamentos entre os diferentes contextos e o termo arena corresponde a cada contexto, que conta com a presença, em geral conflitante, de textos e discursos variados. Para Ball (2001), considerando as ideias de rede e arena, há uma circulação permanente de sentidos nas políticas públicas, o que o leva a incluir o termo "contínuo" em sua abordagem. De ciclo de políticas públicas, sua abordagem passa então a ser denominada "ciclo contínuo de políticas públicas". Nessa perspectiva, as políticas públicas são constantemente ressignificadas, de acordo com quem as lê, interpreta-as e as executa.

Para descrever o macrocontexto e o microcontexto, o autor define cinco contextos que podem ser entendidos como arenas políticas, a partir dos quais todo e qualquer processo de produção de políticas públicas educacionais deve ser analisado: (1) o contexto de influência, relacionado aos textos e discursos que interferem na produção das ideias iniciais de geração de uma política pública; (2) o contexto da definição de texto político, esfera na qual os documentos oficiais são produzidos; (3) o contexto da prática, onde são concretizadas as ações referentes às políticas públicas; (4) o contexto dos resultados e efeitos, referente à avaliação das políticas públicas depois de 
DOI: http://dx.doi.org/10.20396/zet.v25i3.8648349

implementadas e (5) o contexto da estratégia política, no qual são pensadas novas estratégias (ou novas políticas públicas) a partir da avaliação realizada no contexto anterior.

Neste estudo são analisadas as diferentes "vozes" que habitam os contextos da definição de texto e da prática institucional, e nesse sentido o objetivo geral deste trabalho pode ser compreendido à luz da afirmação de Ball (2006, p. 27) de que "uma coisa é considerar os 'efeitos' das políticas sobre coletividades sociais abstratas, outra é conseguir capturar a interação complexa de identidades, interesses, coalizões e conflitos nos processos e atos das políticas".

De acordo com Lopes (2005) e Dias (2009), o processo de recontextualização é fundamental para aproximar as análises entre macrocontexto e microcontexto, pois permite identificar as influências que os discursos de cada contexto sofrem. Por exemplo, a elaboração do texto das orientações curriculares da SME-SP conta com a participação de vários profissionais da própria secretaria e de consultores externos. Como cada um tem sua história de vida profissional e pessoal e vivencia uma experiência particular na produção do documento, são vários os pontos de vista sobre o texto e sua implantação na rede municipal de ensino. Assim, no contexto da produção de texto, pode-se afirmar que o documento já apresenta várias "vozes", que resultam na expressão de um único texto, o texto escrito e oficial; na fala dos colaboradores externos ou dos funcionários da SME-SP, o documento já é outro (ou outros); e quando ele chega às escolas e, mais propriamente, à sala de aula, é mais uma vez transformado, isto é, recontextualizado.

\section{Formação continuada de professores que ensinam matemática}

Diante da necessidade das políticas públicas de aprimoramento da qualidade do ensino e da variedade de fatores cada vez mais imbricados na prática docente, sobretudo a partir dos anos 1990, o professor passa a ser visto como um profissional de múltiplas competências e não mais como um operário da Educação, que, em outras épocas, bastava se especializar em determinada área do conhecimento para transmitir seus saberes aos alunos. Como afirma Imbernón (2010, p. 8),

Se focarmos no campo do professor, poderemos perceber uma falta de delimitação clara de suas funções, que implica a demanda de soluções dos problemas derivados do contexto social e o aumento de exigências e competências no campo da educação, com a consequente intensificação do trabalho educacional - o que coloca a educação no ponto de vista das críticas sociais e educativas.

Diante das novas exigências estabelecidas para o profissional professor e considerando tanto a formação inicial como a continuada, alguns autores têm abordado o tema de forma mais global, referindo-se ao que eles denominam de "desenvolvimento profissional docente". 
DOI: http://dx.doi.org/10.20396/zet.v25i3.8648349

Segundo André (2010), citando Garcia, a preferência pelo termo "desenvolvimento profissional docente" é justificada mediante as mudanças que o ensino vem enfrentando.

A preferência pelo seu uso é justificada por Marcelo [...] porque marca mais claramente a concepção de profissional do ensino e porque o termo desenvolvimento sugere evolução e continuidade, rompendo com a tradicional justaposição entre formação inicial e continuada. [...] Marcelo Garcia [...] nos explica que o conceito sofreu modificações na última década, em decorrência da evolução em nosso entendimento de como correm os processos de aprender a ensinar. Dessa forma, o desenvolvimento profissional passa a ser considerado, segundo ele, como "um processo a longo prazo, no qual se integram diferentes tipos de oportunidades e experiências planificadas sistematicamente para promover o crescimento e o desenvolvimento profissional". (André, 2010, p. 175, destaques da autora)

A ideia de "desenvolvimento profissional docente" ainda está distante das práticas de formação inicial ou continuada. O que se observa, por exemplo, nos cursos de Pedagogia e das demais licenciaturas é uma insegurança e uma imobilidade dos formadores frente às novas exigências do ensino e ao perfil atual do estudante que ingressa na universidade. Isto pode ser verificado nos resultados do estudo realizado por André et al. (2010) sobre o trabalho docente do professor formador, em que se apresenta a falta de perspectiva dos professores dessa área. Muitos depoimentos desses formadores apontam para a falta de preparo do ingressante no que diz respeito às habilidades escolares básicas, e também para a necessidade de "segurar" esse aluno no curso, visto que ele não se sente nada estimulado para o exercício de sua carreira, quando se conscientiza da crise da escola brasileira.

Independentemente da qualidade da formação inicial recebida, o professor passa pela experiência de um curso de graduação, ao longo de três ou quatro anos, frequentando aulas, participando de discussões e lendo textos em diferentes disciplinas, vivenciando situações de estágio, entre outras atividades complementares. Este estudo alinha-se com a perspectiva de Marcelo (apud André, 2010) de considerar a formação inicial e a formação continuada como ações complementares na carreira do professor e, assim, apoia a ideia de que qualquer proposta de formação continuada de professores deveria partir daquilo que o professor já conhece, não só no que se refere a sua prática docente, como também ao que lhe foi oferecido em sua formação inicial.

As críticas, em geral, apontam para uma formação inicial incipiente, repleta de lacunas, que forma professores incapazes de assumir uma sala de aula. Embora o foco deste estudo não seja nem envolva diretamente a formação inicial de professores, propõem-se algumas reflexões sobre o tema que, de alguma forma, relacionam-se com a formação continuada. Será que ao professor recém-formado é oferecida a oportunidade de apresentar, na prática, aquilo que ele conhece, estuda e aprende na graduação e de expressar suas intenções pedagógicas, muitas vezes marcadas pelo interesse na mudança? Será que as escolas públicas ou privadas já não ditam, desde o início, ao novo 
DOI: http://dx.doi.org/10.20396/zet.v25i3.8648349

professor, seja por orientações curriculares oficiais ou por uma tradição de ensino, o "o que" e o "como" ensinar, tolhendo as ações do aluno egresso das licenciaturas?

Os programas destinados aos professores em exercício, além de não considerarem a formação inicial, normalmente priorizam ações voltadas para o domínio de parâmetros e orientações curriculares e das habilidades exigidas nas avaliações externas, medidas que estão bem longe de considerar a concreta realidade da prática docente. Existe, por parte dos órgãos gestores da Educação (este é o caso da SME-SP, na gestão de 2005 a 2012), a tendência em supervalorizar os resultados das avaliações externas e, a partir deles, definir as pautas dos encontros de formação continuada de professores, com a crença de que o problema do baixo rendimento dos alunos pode ser resolvido com a oferta de cursos genéricos aos professores. Tal prática gera um conhecimento descontextualizado da realidade da sala de aula e não atinge o professor em suas demandas cotidianas do fazer docente.

Ao discutir os saberes dos professores, Tardif vincula-os diretamente ao trabalho, afirmando que "as relações dos professores com os saberes nunca são relações estritamente cognitivas: são relações mediadas pelo trabalho que lhes fornece princípios para enfrentar e solucionar situações cotidianas" (Tardif, 2002, p. 17).

Muitas vezes, o professor é forçado a modificar sua prática mediante as orientações e prescrições que ele recebe em sua formação continuada, o que causa, de acordo com Imbernón (2010), um "curto-circuito". Segundo o texto do relatório do estudo da Fundação Victor Civita (2011) sobre formação continuada de professores, que cita Imbernón, os processos de formação continuada devem durar tempo suficiente para que o professor possa refletir e analisar teórica e concretamente suas novas possibilidades de atuação.

Cabe destacar, como bem argumenta Imbernón (2010), que as práticas formativas que promovem demonstrações e/ou simulações de práticas vividas pelos professores podem ser realmente significativas caso consigam ultrapassar a fase de explicação. Isso implica acompanhamento e retorno aos professores para que eles possam viabilizar, em sua prática pedagógica, a inovação difundida na Formação Continuada. Para o autor, é preciso evitar processos inacabados na Formação Continuada, pois eles representam "curto-circuitos", para utilizar seu termo. Explica que esses últimos ocorrem quando a formação exige do professor que ele faça mudanças em sua prática pedagógica, sem que esteja devidamente convencido, teórica e experiencialmente, de que elas são necessárias. Sempre que as práticas formativas desconsiderarem o contexto em que o docente atua e desrespeitarem o tempo de que ele necessita para apropriar-se das novas propostas, os "curto-circuitos" ocorrerão. (Fundação Victor Civita, 2011, p. 69)

No Brasil, a prática do desenvolvimento profissional docente é pouco considerada pelas políticas públicas voltadas para a formação continuada de professores, pois, em geral, elas ainda estão pautadas naquilo que é externo à sala de aula, como, por exemplo, os resultados das avaliações de larga escala e as propostas curriculares. O processo de aprendizagem do professor ainda é concebido como sendo 
DOI: http://dx.doi.org/10.20396/zet.v25i3.8648349

"de fora para dentro", isto é, embora dotado de crenças e modos de pensar próprios, o professor é considerado um sujeito que se constrói profissionalmente por meio da aquisição de novos conhecimentos, exteriores à sala de aula.

Embora a formação venha sendo tratada de modo mais amplo nos últimos anos - considerando as características do contexto, os saberes do professor etc. -, ainda se considera o professor como um objeto de estudo e reforma, geralmente se relacionando a um movimento de fora para dentro, no qual o professor deve se esforçar para assimilar conhecimentos e suprir suas carências tendo a teoria como base e ponto de partida. Na perspectiva do desenvolvimento profissional, ele torna-se sujeito ativo e responsável por seu crescimento e formação contínuos. (Ferreira, 2003, p. 35)

Segundo Ferreira, em artigo que aborda especificamente a formação de professores de Matemática, o desenvolvimento profissional docente começa antes mesmo da formação inicial e se complementa a cada dia, na sala de aula, pois "a prática é a base para um relacionamento dialético entre teoria e prática e, muitas vezes, ponto de partida" (Ferreira, 2003, p. 35).

Para desenvolver o tema "formação continuada de professores que ensinam Matemática", este estudo apoia-se nas três dimensões do conhecimento matemático e dos saberes matemáticos dos professores, apontadas por Moreira e David (2005): a Matemática científica, a Matemática escolar e a prática escolar. Inicialmente, os autores se referem às duas primeiras dimensões, de modo a esclarecer a diferença entre ambas e a opção que fazem por determinada conceituação de Matemática escolar.

Ao tratar da Matemática científica (ou acadêmica), Moreira e David (2005, p. 20) referem-se à Matemática "como um corpo científico de conhecimentos, segundo a produzem e a percebem os matemáticos profissionais". Ao conceituar Matemática escolar, os autores explicam que não adotam a ideia de transposição didática de Chevallard (apud Moreira \& David, 2005), que concebe a Matemática escolar como uma adaptação dos conceitos, técnicas e, consequentemente, valores da Matemática científica. Ao mesmo tempo, os autores não se coadunam com a perspectiva de Chervel (1990, apud Moreira \& David, 2005), que, ao tratar da história das disciplinas escolares, ancora-se na premissa de que elas são "independentes, numa certa medida, de toda a realidade cultural exterior à escola, e desfrutando de uma organização, de uma economia interna e de uma eficácia que elas não parecem dever a nada além delas mesmas, quer dizer, à sua própria história” (Chervel , 1990, p. 180 apud Moreira \& David, 2005, p. 19).

Diferentemente de Chevallard e de Chervel, Moreira e David (2005) conceituam a Matemática escolar considerando, em primeira instância, a prática docente:

Adotaremos uma concepção de Matemática Escolar que não se refira tão estritamente às práticas efetivas que se desenvolvem no interior da escola, como sinaliza Chervel, nem se reduza a uma adaptação da Matemática Científica ao processo de escolarização básica, como sugere Chevallard. [...] Matemática Escolar referir-se-á ao conjunto dos saberes "validados", associados 
DOI: http://dx.doi.org/10.20396/zet.v25i3.8648349

especificamente ao desenvolvimento do processo de educação escolar básica em Matemática. Com essa formulação, a Matemática Escolar inclui tanto saberes produzidos e mobilizados pelos professores de Matemática em sua ação pedagógica na sala de aula da escola, quanto resultados de pesquisas que se referem à aprendizagem e ao ensino escolar de conceitos matemáticos, técnicas, processos etc. Dessa forma, distanciamo-nos, em certa medida, de uma concepção da Matemática Escolar que a identifica com uma disciplina "ensinada" na escola, para torná-la como um conjunto de saberes associados ao exercício da profissão docente. (Moreira \& David, 2005, p. 20-21, destaque dos autores)

A partir da conceituação de Matemática científica e Matemática escolar, os autores abordam os saberes e os "não saberes" da prática docente que fazem parte do processo de formação profissional do professor.

A divisão do conhecimento matemático em científico e escolar se reproduz nos saberes do professor. Por um lado, há o saber disciplinar científico, associado à Matemática científica; por outro lado, há o conhecimento pedagógico da disciplina, que contempla as orientações curriculares e as experiências didáticas. Para Moreira e David (2005), uma das principais consequências dessa divisão é que o saber disciplinar científico ainda é visto, mesmo que de forma implícita, como preponderante ao outro, sobretudo na área da Matemática.

Além desses dois tipos de saberes, os autores destacam os que se desenvolvem na prática profissional docente. Os "saberes da experiência" são fruto de recontextualizações críticas que o professor faz dos saberes científicos e escolares recebidos em sua formação. Isso significa que:

Os saberes da experiência adquirem também uma certa objetividade em sua relação crítica com os saberes curriculares, das disciplinas e da formação profissional. [...] Os professores não rejeitam em sua totalidade os outros saberes; pelo contrário, eles os incorporam à sua prática, porém re-traduzindoos em categorias do seu próprio discurso. Nesse sentido a prática aparece como um processo de aprendizagem através do qual os professores re-traduzem sua formação e a adaptam à profissão, eliminando o que lhe parece inutilmente abstrato ou sem relação com a realidade vivida. (Tardif et al. apud Moreira \& David, 2005, p. 39)

Embora Moreira e David (2005) discorram sobre os cursos de licenciatura em Matemática, é possível utilizar a mesma ideia para a formação de professores dos anos iniciais do ensino fundamental que se apropriam ou necessitam dos saberes matemáticos, dentre os de outras disciplinas referentes ao ensino desse segmento da escolaridade.

Os saberes, sejam eles adquiridos nas formações inicial ou continuada, sejam desenvolvidos na própria prática docente, definem as ações do professor na sala de aula. Por vezes, tais ações estão mais harmonizadas com determinado tipo de saber ou com outro, o que depende da ênfase das formações que o professor recebeu e de sua experiência profissional. 
DOI: http://dx.doi.org/10.20396/zet.v25i3.8648349

Outro aspecto apontado por Moreira e David (2005) refere-se aos "não saberes" do professor. Para os autores, os saberes do professor incluem seus "não saberes". Normalmente, os professores iniciam sua carreira profissional despreparados para o exercício da prática docente; à medida que atravessam seus anos de docência, eles desenvolvem ações que advêm do "não saber o que fazer". Ora, os "não saberes" acabam por se constituir em saberes, uma vez que essas ações são internalizadas pelos docentes e raramente questionadas ou confrontadas com outras práticas.

Sendo assim, a nossa reflexão sobre esse ponto é a seguinte: do mesmo modo que se coloca, para o processo de formação do professor, a questão de conhecer a natureza do saber produzido na prática docente, há que se compreender também a natureza dos "não-saberes" associados a essa mesma prática. Mas, para isso, é preciso situar esses "não-saberes" no interior do processo de educação matemática escolar ao invés de concebê-lo, pura e simplesmente, como uma falta em relação ao conhecimento matemático científico. (Moreira \& David, 2005, p. 43)

Um professor do $5^{\circ}$ ano do ensino fundamental omite em seu ensino, por exemplo, o conteúdo "frações", previsto no programa da escola onde leciona, por não dominar esse conteúdo ou por não dominar o ensino desse conteúdo? Ambas as razões podem coexistir, mas certamente a primeira não existe sem a segunda. Provavelmente, nenhum professor vai desejar se apropriar do conteúdo frações sem estabelecer uma relação direta com seu ensino. Assim sendo, sanar um "não saber" referente à Matemática científica não contribui necessariamente para as situações de ensino. Como afirmam Moreira e David (2005), para serem diagnosticados e discutidos, os "não saberes" devem ser inseridos na dimensão da Matemática escolar e da prática escolar.

Para ensinar frações, um professor do $5^{\circ}$ ano precisa compreender o conteúdo a ser ensinado, sabendo, por exemplo, que $1 / 4$ é maior que $1 / 5$ ou o que significam frações equivalentes. Para isso, os cursos ou encontros, sejam eles de formação inicial ou continuada, deveriam inevitavelmente revisar tais conteúdos de uma escolaridade que ficou para trás, porém sempre os contextualizando no ensino e na prática escolar.

Em resumo, o saber docente deve ir além do conhecimento do conteúdo e das formas de ensinar Matemática, integrando as três dimensões do saber do professor, associadas à Matemática científica, à Matemática escolar e à prática docente. Por exemplo, para trabalhar estratégias de cálculo com alunos de $3^{\circ}$ ou $4^{\circ}$ ano, o professor precisa: a) conhecer as diferentes formas de calcular, o que inclui desde o uso da calculadora ao domínio das técnicas algorítmicas; b) apropriar-se de dinâmicas de aula que estimulem a aprendizagem dos alunos; e c) conhecer meios de validar seus saberes na realidade local em que desenvolve sua prática docente.

\section{A pesquisa}


DOI: http://dx.doi.org/10.20396/zet.v25i3.8648349

A pesquisa desenvolve-se de acordo com a abordagem qualitativa de análise, uma vez que envolve a interpretação de documentos e de depoimentos de profissionais da SME-SP.

A partir da perspectiva teórica e metodológica de Ball sobre políticas públicas educacionais, que sugere uma análise interdependente do macrocontexto e do microcontexto, procura-se extrair, como afirma Chizzotti (2003, p. 221), "os significados visíveis e latentes" das questões ligadas à formação continuada de professores, por meio da leitura e da interpretação de textos oficiais, da observação de encontros de formação continuada de professores promovidos pela SME-SP e da análise do depoimento de duas professoras acerca das políticas públicas implantadas na rede municipal de ensino e de suas práticas em sala de aula.

Inicialmente, são analisados nove documentos produzidos ao longo da gestão Serra-Kassab que tratam direta e indiretamente da formação continuada de professores, dentre eles, portarias normativas, publicações com orientações didáticas ao coordenador pedagógico e ao professor e as orientações curriculares, documento considerado o currículo oficial da rede municipal de ensino naquela gestão de governo. Como complemento da análise documental, é realizada uma entrevista com uma das assessoras da SME-SP, responsável pela formação continuada de professores, em Matemática, de toda a rede. Em um segundo momento, analisa-se elementos observados e documentados de uma prática composta por quatro encontros de formação continuada de professores, em Matemática, promovida por uma das Diretorias Regionais de Ensino (DRE) da SME-SP em 2012 e oferecida a professores do $4^{\circ}$ ano do ensino fundamental de oito anos. Nesta fase da pesquisa, a formadora que ministra os encontros também é entrevistada. E finalmente, são examinados os dados provenientes de entrevistas realizadas com duas professoras que participam dos encontros de formação continuada observados. Nas entrevistas, as professoras apresentam comentários sobre parte dos documentos analisados, a formação continuada da qual participaram e as demandas da prática docente.

\section{Análise dos resultados}

O conjunto de documentos analisados explicita uma concepção de formação continuada de professores da SME-SP na gestão Serra-Kassab centrada em "eventos", de acordo com o que os gestores decidem como sendo prioridade. Por exemplo, o Programa Ler e Escrever, grande marco da gestão, lançado em 2006, define várias ações e dentre elas a formação continuada de professores é apenas uma. $\mathrm{O}$ foco das políticas públicas não é, portanto, a formação continuada de professores, que é definida como uma ação condicionada a outros projetos principais.

Nos documentos oficiais, nos encontros de formação continuada e nas entrevistas - com a assessora da SME-SP e com a formadora -, o professor é visto como um profissional de formação inicial deficitária, que necessita de orientações minuciosas sobre como ministrar suas aulas. Embora os documentos não abordem 
DOI: http://dx.doi.org/10.20396/zet.v25i3.8648349

diretamente aspectos da formação inicial do professor dos anos iniciais, a análise documental é atravessada pela ideia de um profissional recém-formado que "pouco aprende" no curso de graduação e muito reproduz um ensino que recebeu em sua escolaridade. Sobretudo nos documentos de natureza instrucional, há, por exemplo, mensagens que indicam a existência de professores mal preparados, que deturpam ou não colocam em prática as novas teorias.

[...] muitas deformações na prática docente foram se consolidando por influência de visões deturpadas das próprias teorias educacionais. Uma ideia bastante comum é a de que, em uma perspectiva construtivista, o percurso de aprendizagem deve ser ditado unicamente por interesses dos alunos, sem definições prévias de objetivos e conteúdos. (São Paulo \& Fundação Padre Anchieta, 2010, p. 10)

Ademais, o passo a passo do "como fazer" na sala de aula, presente em alguns textos, é tão minucioso que também não deixa de expressar uma maneira de conceber o papel do professor e da sua formação. O tom prescritivo das orientações revela falta de confiança no preparo do professor e desconsideração de seus anseios e autonomia. Isso está claramente expresso em um dos vários encaminhamentos de atividade, ao professor, do "Guia de planejamento e orientações didáticas para o professor do $4^{\circ}$ ano do Ciclo I", que tem esse sentido.

Distribua a folha da atividade e diga para que façam a leitura do enunciado. Certifique-se de que todos entenderam a tarefa a ser realizada. Percorra a sala observando quais são as estratégias utilizadas pelas diferentes duplas e anote as que considerarem mais interessantes para serem socializadas. Quando você perceber que os alunos já ficaram tempo suficiente para tentarem resolver todas as atividades, faça a socialização na lousa. (São Paulo, 2008, p. 237)

No discurso da formadora, a mesma ideia está presente, sobretudo quando ela faz referência a práticas docentes que julga inadequadas; é como se o professor nunca tivesse recebido orientações para agir distintamente, o que está diretamente relacionado à sua formação inicial.

Nota-se que nos encontros de formação continuada os professores são considerados receptores "ativos" do texto dos documentos; em momento algum, a prática da sala de aula, as dificuldades e os interesses que eles trazem para o curso são problematizados e, quando ocorre algo nesse sentido, a prática refere-se à retomada das atividades a serem aplicadas em sala de aula, propostas pelo formador. Dessa forma, a concepção de formação continuada de professores presente tanto nos documentos como nas práticas formativas parte do meio externo, isto é, de contextos que não correspondem à prática da sala de aula. Ela é planejada e promovida a partir das orientações curriculares da SME-SP, dos resultados do desempenho dos alunos nas avaliações externas e até mesmo da necessidade de sanar problemas emergenciais na rede de ensino, como é o caso dos encontros analisados neste trabalho, organizados para atender uma demanda específica da secretaria que consistia no atendimento dos alunos do $4^{\circ}$ ano do ensino fundamental de oito anos candidatos à reprovação. 
DOI: http://dx.doi.org/10.20396/zet.v25i3.8648349

Os documentos oficiais e as ações formativas da SME-SP são resultantes de uma mistura de lógicas recontextualizadas, nas quais as diferenças existentes entre os envolvidos (opostas ou não) são negociadas. Por exemplo, a lógica do discurso oficial da secretaria e a lógica interna de cada elaborador dos documentos sobre o que significa ensinar e aprender Matemática se mesclam e, para a definição dos textos oficiais, as diferenças entre essas lógicas precisam ser negociadas. Como afirma Lopes (2005), referindo-se à superação das concepções baseadas na divisão em oposições binárias global-local, totalidade-singularidade, identidade-diferença, dentre outras - e à inevitável existência de ações híbridas, "não se trata de um processo de assimilação ou de simples adaptação, mas um ato em que ambivalências e antagonismos acompanham o processo de negociar a diferença com o outro" (Lopes, 2005, p. 59). A negociação também pode ser verificada nos encontros de formação continuada, onde a formadora e as professoras negociam seus saberes e não saberes frequentemente. As professoras reconhecem como promissoras as ideias da formadora, porém, ao mesmo tempo, apresentam a vivência da sala de aula como fator limitador da prática docente e, com isso, esperam da formação recebida orientações sobre como agir diante dos problemas enfrentados no dia a dia. Da mesma forma, ocorre com o texto dos documentos oficiais, lidos e colocados em prática de maneira parcial pelos professores.

$\mathrm{Na}$ "voz" das professoras entrevistadas, evidencia-se o fato de que nem tudo que é proposto é possível de ser feito, uma vez que na sala de aula há fatores que impõem limitações, como as dificuldades de aprendizagem e a indisciplina dos alunos.

\section{Considerações finais}

Considerando os resultados da investigação, conclui-se que não há a devida clareza por parte de todos os envolvidos nas políticas públicas educacionais de formação continuada da SME-SP - do elaborador do currículo ao professor - sobre o objeto de negociação. O que está sendo negociado: a melhoria do ensino e da aprendizagem ou a elevação dos índices de desempenho dos alunos nas avaliações externas? Embora a secretaria conceba uma relação causal entre tais ações, ela não existe de fato, pois a lógica de instrumentalizar o professor para ensinar melhor de modo que o aluno realmente aprenda é diferente da lógica de lhe oferecer condições para que ele prepare seus alunos no enfrentamento das avaliações externas.

Além do mais, há uma inadequação na definição de políticas públicas que produzem orientações curriculares que não dialogam com a realidade do professor e do aluno. Esse tipo de ação cria um cenário de "faz de conta" (mesmo que inconsciente!) na SME-SP, onde professores parecem ensinar e alunos, orientados na maioria das vezes apenas a obterem um bom desempenho nas avaliações oficiais externas, parecem aprender.

Políticas públicas que se baseiam nos resultados de avaliações externas, elaboradas a partir de objetivos ou expectativas de aprendizagem distantes da realidade 
DOI: http://dx.doi.org/10.20396/zet.v25i3.8648349

não se efetivam a contento, pois transitam em um ciclo de poucas possibilidades de mudança, devido à distância entre o que se espera do aluno e o que de fato ocorre, na prática, no processo de ensino e aprendizagem. No caso da gestão de 2005 a 2012 da SME-SP, as primeiras ações têm por base o desempenho dos alunos das escolas da Rede Municipal de Ensino de São Paulo nas avaliações externas dos anos anteriores. Resultados aquém do esperado geram políticas públicas que continuam distantes da realidade da rede, modificando quase nada o que já existe.

O fato de as políticas públicas fazerem parte de um inevitável ciclo contínuo (Ball, 2001) não se constitui um conflito. As ideias circulam e em cada contexto elas se transformam; esse movimento é previsto e sempre presente. O problema corresponde ao fato da dimensão global ainda prevalecer sobre a dimensão local, ou seja, das ações de formação continuada de professores ainda acompanharem o movimento "do externo para o interno", de modo verticalizado, e consequentemente a realidade daquilo que efetivamente ocorre na sala de aula, e que concerne especialmente à prática, à experiência e ao que pensa o professor, não ser devidamente considerada. Assim, o ciclo contínuo das políticas públicas torna-se um círculo vicioso, sem que novos elementos provenientes da vida da sala de aula possam renová-lo. Isso explica o motivo de, em oito anos de gestão, propostas da SME-SP terem provocado mudanças inexpressivas na prática docente.

O que é necessário para que políticas públicas educacionais de um município com a dimensão de São Paulo possam realmente se efetivar? Primeiramente, as secretarias de Educação devem assumir a formação continuada de professores como uma política pública central e não apenas como ações episódicas no interior de outros projetos ou políticas, como, por exemplo o sistema das avaliações externas ou da produção de materiais didático oficiais, os quais trazem como premissa a necessidade de preparar o professor para a sua execução. Além disso, essa política pública central precisaria estabelecer articulações com as questões que inquietam e mobilizam o interesse do professor, relativas à sua atuação. Elaborar materiais instrucionais não é uma política pública central de formação continuada de professores, sobretudo quando os principais atores não estão envolvidos nesse processo (o "envolvimento" passa a ser tão somente a execução de algo pensado por outrem), assim como criar mecanismos de avaliação dos alunos em larga escala muito pouco contribui para o aperfeiçoamento da prática docente. Tomar a formação continuada como política pública central significa, antes de tudo, contar com a participação do professor, cuja "voz" carrega as recontextualizações constituídas ao longo de sua de formação e desenvolvimento profissional e expressa seus reais interesses.

\section{Referências}

André, M. (2010). Formação de professores: a constituição de um campo de estudos. Revista Educação, 33(3), 174-181. Retirado em 21 de fevereiro, 2017, de: http://revistaseletronicas.pucrs.br/ojs/index.php/faced/article/view/8075/5719. 
DOI: http://dx.doi.org/10.20396/zet.v25i3.8648349

André, M., Almeida, P., Hobold, M., Ambrosetti, N., Passos, L., \& Manrique, A. (2010). O trabalho docente do professor formador no contexto atual das reformas e das mudanças no mundo contemporâneo. Revista Brasileira de Estudos Pedagógicos, 91(227), 122-143. Retirado em 21 de fevereiro, 2017, de: http://rbep.inep.gov.br/index.php/rbep/article/view/606/587.

Ball, S. (2001). Diretrizes políticas globais e relações políticas locais em educação. Currículo sem fronteiras, 1(2), 99-116. Retirado em 21 de fevereiro, 2017, de: http://www.curriculosemfronteiras.org/volliss2articles/ball.pdf.

Ball, S. (2006). Sociologia das políticas educacionais e pesquisa crítico-social: uma revisão pessoal das políticas educacionais e da pesquisa em política educacional. Currículo sem fronteiras, 6(2), 10-32. Retirado em 21 de fevereiro, 2017, de: http://www.curriculosemfronteiras.org/vol6iss2articles/ball.pdf.

Chizzotti, A. (2003). A pesquisa qualitativa em ciências humanas e sociais: evolução e desafios. Revista Portuguesa de Educação, 16(2), 221-236. Retirado em 21 de fevereiro, 2017, de: http://www.redalyc.org/articulo.oa?id=37416210.

Dias, R. E. (2009). Ciclo de políticas curriculares na formação de professores no Brasil (1996 - 2006). Tese de Doutorado em Educação. Rio de Janeiro: Faculdade de Educação da Universidade do Estado do Rio de Janeiro. Retirado em 21 de outubro, 2014, de:

http://www.curriculo-uerj.pro.br/imagens/pdfTeses/CICLO_DE_P_71.pdf.

Ferreira, A. C. (2003). Um olhar retrospectivo sobre a pesquisa brasileira em formação de professores de matemática. In: D. Fiorentini (Org.). Formação de professores de matemática: explorando novos caminhos com outros olhares (pp. 19-40). Campinas: Mercado de Letras.

Fundação Victor Civita (2011). Formação continuada de professores: uma análise das modalidades e das práticas em estados e municípios brasileiros - relatório final. São Paulo: Fundação Carlos Chagas. Retirado em 21 de outubro, 2014, de: http://fvc.org.br/pdf/relatorio-formacao-continuada.pdf.

Imbernón, F. (2010). Formação continuada de professores. Porto Alegre: Artmed.

Lopes, A. C. (2005). Política de currículo: recontextualização e hibridismo. Currículo sem Fronteiras, 5(2), 50-64. Retirado em 21 de fevereiro, 2017, de: http://www.curriculosemfronteiras.org/vol5iss2articles/lopes.pdf.

Lopes, A. C. (2006). Discursos nas políticas de currículo. Currículo sem Fronteiras, 6(2), p. 33-52. Retirado em 21 de fevereiro, 2017, de: http://www.curriculosemfronteiras.org/vol6iss2articles/lopes.pdf.

Moreira, P. L., \& David, M. M. M. S. (2005). A formação matemática do professor: licenciatura e prática docente escolar. Belo Horizonte: Autêntica.

São Paulo (SP). Secretaria Municipal de Educação. Diretoria de Orientação Técnica. (2008). Guia de planejamento e orientações didáticas para o professor do $4^{o}$ ano do Ciclo I. São Paulo: SME/DOT. Retirado em 22 de janeiro, 2015, de: http://portal.sme.prefeitura.sp.gov.br/Portals/1/Files/17248.pdf. 
DOI: http://dx.doi.org/10.20396/zet.v25i3.8648349

São Paulo (SP). Secretaria Municipal de Educação, Fundação Padre Anchieta. (2010). Cadernos de apoio e aprendizagem: Matemática. Programa de orientações curriculares. Livro do professor. $5^{\circ}$ ano $/ 4^{\circ}$ ano do ensino fundamental de oito anos. São Paulo: Fundação Padre Anchieta.

Tardif, M. (2002). Saberes docentes e formação profissional. Petrópolis: Vozes. 